\title{
Research on online teaching of college teachers under the background of education informatization
}

\author{
Xiangli Dong, ${ }^{1, *}$, and Xiaoyu Chen $^{2}$ \\ ${ }^{1}$ Shandong Xiehe University, Computer Science Department, Yaoqiang Town, Licheng District, \\ Jinan City, China
}

\begin{abstract}
With the rapid development of information technology, educational informatization is the popularization and penetration of information technology. At present, online teaching has been implemented all over the world, which is a practical reform of educational informatization. This paper discusses the teaching concept, platform selection, study situation analysis, resource preparation, curriculum implementation, summary and reflection and other aspects of the curriculum under the background of educational informatization, so as to do a good job in the organization and management of online teaching under the background of educational informatization, and lay a foundation for the innovative practice of information-based leading educational concept and education mode.
\end{abstract}

\section{Introduction}

In the Internet era, educational information technology leads to the reform of teaching concept, teaching mode, teaching method, teaching organization and other aspects. In the first half of 2020, online teaching will be carried out in colleges and universities across the country to make full use of the deep integration of modern information technology and education and teaching. In order to ensure the effective organization and implementation of online teaching, some colleges and universities have built a wealth of online resources. They can make use of online MOOC and online course teaching resources and actively carry out online teaching activities relying on various online course platforms at all levels. The Ministry of Education has also organized more than 20 free online courses on online course platforms, requiring college teachers to correctly guide students to study independently online. This is a successful practice of promoting educational informatization, which effectively promotes the development of educational informatization in the depth and breadth of education, and promotes the overall improvement of the professional level of college teachers and the quality of online teaching. With the development of information technology, especially intelligent technology, intelligent education has become the trend of the world, which is also the need of the development of China's education itself[1]. Online

\footnotetext{
*Corresponding author:778118795@gq.com
} 
education needs to change from "novelty" to "new normal". The integration of "Internet +" and "intelligent + " technology online teaching has become an important development direction of Higher education in China and the world[2].It is a strategic choice for China's educational reform and development in the new era to lead educational modernization with the support of educational informationization, which is of great significance for building a strong country in education and human resources.

\section{Teaching concept}

Traditional classroom learning is limited, but online teaching has found a new way. Online teaching is a challenge for every teacher, including online teaching cognition, hardware equipment, software technology, and even the teaching environment. The "teaching inertia" or "teaching memory" formed for a long time sometimes has a skeptical attitude, resistance, panic and even rejection behavior towards modern educational technology, and it is even confusing for online teaching [3]. Online teaching to the effective protection of teachers, school leaders create conditions to provide information technology teaching, online training, improve the capacity from the teaching idea, platform selection, teaching design, teaching methods, etc, comprehensive study, two weeks before the holiday normal school, every day more than a training content, understanding of online teaching has a fresh, not imagined the implementation of online teaching. On the contrary, according to the characteristics of the course, if combined with flipped classroom and other mixed teaching modes, sufficient teaching resources are prepared, teaching implementation is carefully designed, and basic platform operation technology is familiar with, online teaching can be competent for traditional teaching tasks, and the teaching effect is beyond people's consistent cognition.

\section{Implementation of online teaching under the background of educational informatization}

\subsection{Teaching platform}

With the large-scale implementation of online teaching, more and more online teaching platforms of colleges and universities have emerged, for example: love course MOOC (China university), the school online, super star general class of network platform, the wisdom tree network super star platform such as colleges and universities, the platform to the national curriculum resources for free, online teaching service, live online lectures, online teacher training services. The choice of platform is an important carrier to ensure the online teaching effect. Each teaching platform has its own characteristics. According to the characteristics of the courses received, one or two teaching platforms should be appropriately selected to ensure the effective implementation of the course teaching, but too many are not recommended. At present, According to the characteristics of the courses, I choose one of the teaching platforms to ensure the effective operation of normal online teaching by combining with QQ sharing screen or Tencent conference and other software. During the teaching process, there may be some problems such as too much load of teaching platform, delayed display of students' learning records, too long transcoding time of course resources, and students' inability to check in time, etc., which may be reported to maintenance personnel in time, and they will deal with and solve them in time according to the situation. In addition, they also do some questionnaires to understand our online needs and keep improving them, which can meet the requirements of online teaching and learning of teachers and students in universities under certain circumstances. 


\subsection{Study situation analysis}

The implementation of online teaching is a brand new experience for college students. Students get rid of the constraints of the school, the supervision of administrators, and the sight of teachers. A small number of students, who are motivated and self-disciplined, will make full use of their time to learn courses related to their major or that they are interested in. Most students spend most of their time with their mobile phones, playing games, playing douyin, playing WeChat and so on almost every day[4]. Every day is flooded with useful, useless, false, and negative information, Some are also spread wantonly, the negative effects are amplified, it is difficult to distinguish the real from the fake, they are trapped in them, their emotions are ups and downs, their life is black and white, their learning is chaotic, Empty life, without the basic sense of self-discipline and enthusiasm for independent learning. In the long run, it will have a significant and lasting impact on college students' study and life as well as their physical and mental health.

\subsection{Resource preparation}

Sufficient teaching resources are the basis for the orderly operation of online teaching. According to the characteristics of the platform and the nature of the course, there are many types of new course resources, such as video, audio, chapter tests, pictures, documents, books, links and animations, which greatly expand the capacity of traditional classroom information. First of all, it is necessary to create a new course. If there is the same or similar ready-made teaching resource package on the platform, it can be imported directly. On the contrary, it is necessary to create a new chapter according to the teaching syllabus, and upload relevant learning resources under the corresponding chapter. It can be self-made, or it is suggested to refer to other resources. In this way, resources can be more targeted, and exclusive resources can be accumulated effectively to provide convenience for future teaching. The resources should be short but not long, and the types should be more or less. Moreover, the relevant knowledge points can be added to the learning content to expand students' thinking with the help of Internet search. Find relevant books from the platform and set the pages of relevant knowledge points as task points for students to refer to and complete theoretical learning. In addition to uploading some necessary chapters, some relevant resources can also be uploaded to the materials to expand students' thinking and broaden their horizon. Of course, students have a lot of learning resources, so teachers should be diversified, personalized, and teach students according to their aptitude. For some of the more practical courses, need to do hands-on experiments. Teachers should do experiment simulation well in advance. Homemade related resources, including simulation software download, installation, use and so on. In addition, the scientific establishment of the test bank, constantly enrich the teaching resources.

\subsection{Curriculum implementation}

Curriculum implementation is the foothold of high-quality online teaching, which is generally divided into three stages: pre-class, in-class and after-class. Before class, a notice is first issued to remind students of class time and inform them to study online in time. Then issue the sign-in, timely statistics of the list of students who did not sign in, contact the school committee, to understand the situation; Finally, the list of learning tasks should be clear and detailed, listing the contents of learning chapters and key points and difficulties, and clarifying the learning objectives and requirements. Let the students learn by themselves according to the task list of this lesson. Ask the students to complete the corresponding task points. At the same time, take out paper and pen to make notes of 
important knowledge points and input knowledge. In class, it is an important stage of online teaching. Through the teaching process of platform function design in class, teachers should enrich online teaching activities and provide good guidance. According to the students answer questions in time, students participate in learning enthusiasm to improve. For some courses with strong operability, students can study in groups and practice while speaking. Also, learning groups can be formed according to students' conditions. Students can be taught in accordance with their aptitude to develop their independent learning ability, confidence in learning and improve learning efficiency. After the completion of a chapter, students are required to take a test to check their learning status. In terms of the difficulty in dividing the questions, students are required to master the basic knowledge of this chapter, adjust the teaching content according to the score, timely understand the problems encountered by students in the learning process, and help students solve the problems. After class, increase online interaction, teachers and students to discuss together, in the depth of research out of the spark of thinking, can be more direct and timely understanding of the students master. Summarize students' performance in class and course content, assign homework, evaluate each other, complete knowledge output, internalization and sublimation, and consolidate what they have learned.

\section{The deficiency of online teaching under the background of education informatization}

Online teaching is not limited in space and time. It can also support after-class review. Students can directly choose the knowledge they are interested in for learning. However, there are still many deficiencies in realizing the substantial equivalence with offline teaching effect.

\subsection{Teachers' information-based teaching level needs to be improved}

Part of the teaching teachers are weak in modern educational ideas, unskilled in computer and software operation necessary for learning, low in designing and making courseware, lack of necessary information literacy, and need to be improved in training students' ability to take the initiative to obtain information and knowledge. In the face of the change of pedagogy teaching mode, the inertia of traditional classroom education may cause anxiety, cause physical and mental health problems, and lead to have no idear in information education and teaching reform.

\subsection{The online teaching design needs to be optimized}

The design of online teaching plan does not break away from the traditional classroom teaching mode. It is still "cramming" and "cramming", focusing on the imparting of knowledge. The teaching plan is carried out step by step, and there are few teaching activities. Teachers are always acting in a "one-man show". Students seldom communicate with each other online, and it is difficult to feel the learning atmosphere. The evaluation and feedback of teaching activities are not accurate and timely.

\subsection{The online teaching environment needs to be improved}

Under the background of education informatization, online teaching requires higher requirements on the network, and the network varies greatly. In some places, the network coverage is not enough, and in some places, the network signal is unstable and not smooth. 
If the whole learning process of students is to be monitored, the phenomenon of lag is particularly prominent, so students are required to turn off the video during online teaching. However, online classroom monitoring is insufficient, and it is difficult to guarantee students' participation in class, effectively control students' learning situation, or track students' learning. At the same time, it is difficult for students to feel teachers' body language, which leads to teachers' passive teaching and leads to students' differentiation in the long run. With the increasing number of online teaching platform users, the teaching platform is seriously overloaded, which causes great pressure on the server. The advantages of online teaching are not obvious and the teaching effect is poor.

\section{Suggestions on online teaching under the background of education informatization}

Online teaching under the background of education informatization is a great challenge to the cognition, ability and will belief of every college teacher. Online teaching needs an adaptation process. In order to better implement online teaching, the suggestions are as follows:

First of all, improve the teachers' information teaching ability.Under the background of education informatization, online teaching has higher requirements on the informatization teaching ability of college teachers, so teachers must strengthen the consciousness of using information autonomously and consciously. Encourage teachers to participate in training, information-based teaching competition, change education idea and teaching behavior, use computer and other information technology to solve the problems of the teaching, scientific research, cultivate the students' information literacy, innovation spirit and problem solving ability, to enhance the learning ability of students, improve their academic achievement.

Secondly, optimize the teaching design. How teachers design, implement and evaluate teaching activities reasonably, appropriately and scientifically in the informationized environment has become the core part of educational informationization. Good teaching design is the key to a good class. There are many teaching modes of information-based teaching design, so teachers should get rid of the traditional classroom teaching mode, combine with OBE concept, and strengthen the consciousness of results. It integrates the process of "self-study - guide - study - research" into the teaching design. The online teaching has the characteristics of strong interaction, strong timeliness and good display effect, The teachers of online teaching design should fully implement heuristic teaching, interactive communication and critical discussion, and establish an open online teaching mode that focuses on students' online self-study, supplemented by teachers' guidance and answers to questions and doubts [5]. While teaching knowledge, teachers should focus on improving their thinking and ability. Online teaching integrates ideological and political education, which cultivates lofty ideals and beliefs while learning professional knowledge. To realize the change of students from passive acceptance of learning to active exploration of learning, the process from shallow to deep, step by step. In each link of teaching design and teaching activities, it is necessary to evaluate and feedback the teaching design, and adjust the relevant links of teaching design and teaching activities at any time. Evaluation, feedback and modification should run through the whole process of informationized teaching design, so as to achieve the optimization of teaching process.

Finally, optimize the online teaching environment. Online teaching has changed from a traditional face-to-face classroom to a peer-to-peer interaction between teachers and students, improving the quality of the Internet and not focusing on learning in a single period of time. Optimize the online teaching platform, prepare online resources carefully, increase online high-quality interaction, ask questions in class, let students give lectures, implement the principal position of students, study in groups, help in groups, strengthen 
humanistic care and stimulate students' active interest in learning, so as to make up for the absence of online teaching supervision and the difficulty in forming a learning atmosphere.

\section{Summary and reflection}

Online teaching requires the efforts of every educator in order, sufficient and diverse resource supply, comprehensive management services, interactive guidance of teachers and cooperative exploration of students. The teaching design with high order, innovation and challenge needs to be improved, Education under the background of the informationization teaching reform on the road, always need to try, to explore, research, and participate in online training, accumulate experience, positive change teaching idea, innovating teaching mode, around the "Internet + education", "Smart + education" to break the limitations of the traditional teaching mode, promote the deep reform of modern information technology and teaching process, improve the quality of teaching, lay the foundation for innovation education informatization development. It lays a foundation for the reform and innovation of online and offline blended teaching mode in the future.

Shandong Xiehe University vocational Education Innovation development highland theory and practice research special project: Research on the Construction and Application Innovation of hybrid Teaching Resource Database for Internet of Things majors in Vocational colleges under the background of Educational Informatization 3.0 (XHXY202023)

\section{References}

1. Baidu. Market size and Development Trend of intelligent Education industry in 2018 online education and education informatization are making joint efforts [EB/OL]. https://baijiahao.baidu.com/s?id=1636203713072252358.

2. Department of Higher Education, Ministry of Education. College online education about the situation and the next work consideration[EB/OL]. http://www.moe.gov.cn/ fbh/live/2020/51987/sfcl/202005/t20200514_454117.html,2020-05-14.

3. Daguang Wu. Review and Reflection on the Evolution of Educational TechnologyBased on the perspective of online teaching in colleges and universities in the context of COVID-19 epidemic[J]. Higher Education studies in China,2020(04):1-6+11.

4. Under the epidemic situation, what is the group of college students doing? How is the effect to fonline courses[EB/OL]. https://news.163. com/20/0302/11/ F6N82ENR000 18990.html.

5. Hua Bu, Xiazaolu CUI. Discussion on the optimization of online Teaching in colleges and universities [J]. Journal of Higher Education,2020(34):29-32. 